\title{
Outcomes of Congenital Diaphragmatic Hernia: An 8-Year Experience
}

\author{
Minoo Fallahi,, Leily Mohajerzadeh, ${ }^{2,}$ Samira Borhani, ${ }^{1}$ Mohammad Kazemian, ${ }^{1}$ Mohsen Roozroukh, ${ }^{2}$
}

\author{
Ahmad Khaleghnejad-Tabari, ${ }^{2}$ Roxana Azma, ${ }^{3}$ and Alireza Mahdavi ${ }^{3}$ \\ ${ }^{1}$ Neonatal Health Research Center (NHRC), Shahid Beheshti University of Medical Sciences, Tehran, Iran \\ ${ }^{2}$ Pediatric Surgery Research Center, Shahid Beheshti University of Medical Sciences, Tehran, Iran \\ ${ }^{3}$ Shahid Beheshti University of Medical Sciences, Tehran, Iran \\ "Corresponding author: Leily Mohajerzadeh, Pediatric Surgery Research Center, Shahid Beheshti University of Medical Sciences, Tehran, Iran. Tel: +98-2122227033, E-mail: \\ mohajerzadehl@yahoo.com
}

Received 2016 September 25; Revised 2016 December 02; Accepted 2017 February 05.

\begin{abstract}
Background: Congenital diaphragmatic hernia (CDH) is a common congenital anomaly with significant morbidity and mortality. Few surveys have been reported regarding the prenatal status, clinical course and postnatal outcome of CDH. The symptoms and prognosis depend on the location of the defect and associated anomalies.

Objectives: The aim of this study was to examine the effect of clinical factors on the prognosis of CDH in our pediatric hospital. Methods: We analyzed 74 records of $\mathrm{CDH}$ neonates referred to our center for surgery between 2008 and 2015. We investigated the associated factors with the outcomes of $\mathrm{CDH}$ using the information extracted from the hospital records. The perinatal status, clinical course and the postnatal outcome were reviewed. Survival was defined as infants alive at hospital discharge.

Results: A total of $74 \mathrm{CDH}$ cases were identified. Of these, 27 (36.5\%) cases were females and 47 (63.5\%) males. The type of hernia in 73 (98.6\%) cases was Bochdaleck and 1 (1.4\%) case was Morgagni. Seventeen (23.9\%) cases had right-sided CDH and 57 (76.1\%) cases left- sided CDH. Also, 90.5\% underwent open surgery and 9.5\% thoracoscopic repair. Forty-seven (63.5\%) cases survived and 27 (36.5\%) cases succumbed. The survival rate had a significant statistical correlation with the place of delivery. The death rate was higher in neonates referred from other hospitals in our town in comparison to other cities $(P=0.008)$. Also, the resuscitation history, the status at admission (intubated or not intubated) $(\mathrm{P}=0.00)$, existence of skeletal anomalies $(\mathrm{P}=0.02)$ and brain hemorrhage $(\mathrm{P}$ $=0.045$ ) had a significant correlation with the survival rate. The side of herniation, herniated organs, type of operation (open or thoracoscopic), cardiac and renal anomalies and age at the time of surgery had no significant correlation with outcome.

Conclusions: The overall mortality rate in $\mathrm{CDH}$ was high in our series. Neonates with $\mathrm{CDH}$ should be delivered in institutes with the neonatal intensive care unit and surgery ward to prevent complications. To achieve better survival rates, pulmonary hypertension should intensively be controlled and the extracorporeal membrane oxygenation should be used in selected cases.
\end{abstract}

Keywords: Congenital Diaphragmatic Hernia, Congenital Anomaly, Neonate, Bochdaleck Hernia

\section{Background}

Congenital diaphragmatic hernia $(\mathrm{CDH})$ is a severe anomaly with a birth occurrence of 1/4000 neonates (1). There are different prognostic factors in outcome in $\mathrm{CDH}$ infants. Regardless of improvement in intensive neonatal care, it still leads to a high rate of mortality in this group of patients. We carried out a multivariate analysis to identify independent predictors of mortality in our $\mathrm{CDH}$ population.

\section{Methods}

Mofid Children's hospital is a tertiary care referral hospital in Tehran, which has the pediatric surgery and neonatal intensive care unit. After obtaining approval from the ethical committee in our university, we analyzed 74 records of $\mathrm{CDH}$ neonates, which have referred to this hospital for surgery between 2008 and 2015. Neonates with incomplete information or those who were referred to another center were excluded from the study. Information on gestational age, birth weight, age of operation, sex, kind and side of hernia, a positive family history for congenital anomaly, type of delivery and kind of herniated organ as well as findings in an immediate postnatal period including the place of birth, weight, gestational age, Apgar scores at 1 and 5 minutes and the need for the ventilatory support were extracted from hospital records. The perinatal status, clinical course and the postnatal outcome were reviewed. Survival was defined as infants alive at hospital discharge.

All data were entered in an electronic spread sheet and all numerical data are presented as mean \pm standard deviation. Data for survived and deceased infants were compared using t test. $\mathrm{P}<0.05$ was considered as statistically significant. 


\section{Results}

In this study, 74 cases of $\mathrm{CDH}$ were identified with the mean age of 5 days ( 1 - 45 days). The means and standard deviations (SD) of gestational age and birth weight were $37.42 \pm 8$ weeks and $2915.86 \pm 515 \mathrm{~g}$, respectively (Table 1 ). The mean age at the operation was 8 days ( 1 - 45 days). Also, $89.2 \%$ were identified in infancy and $10.8 \%$ in a prenatal period. The mean age at prenatal diagnosis was 35.33 (34 - 36 weeks). Family history for $\mathrm{CDH}$ in all cases was negative. Family history for other congenital anomalies was positive in $4.1 \%$ (2.7\% mental retardation and $1.4 \%$ anencephaly). Of these, 27 (36.5\%) cases were females and 47 (63.5\%) males.

The type of delivery in $33.8 \%$ was natural vaginal delivery (NVD) and 66.2\% was cesarean section (C/S). Also, 25.9\% of the patients had an Apgar score less than 7 and $74.1 \%$ more than 7.

Twenty-seven percent of the parents were product of consanguineous marriage; $52.1 \%$ arrived to our center not intubated and $47.9 \%$ intubated. Also, 37.5\% were connected to mechanical ventilator before the surgery. We did not use high frequency oscillatory (HFOV) in any patient. The mean duration of postoperative ventilator support was 11.5 (1-138) days and the mean hospitalization duration was 20 (1 - 144) days.

The type of hernia in 73 (98.6\%) cases was Bochdaleck and in one $(1.4 \%)$ case was Morgagni.

Seventeen (23.9\%) cases had right-sided and 57 (76.1\%) cases left-sided $\mathrm{CDH}$. Also, $6.8 \%$ of the neonates had pneumothorax before the surgery that needed chest tube insertion. In this study, 90.5\% underwent open surgery and 9.5\% thoracoscopic repair. Herniated organ in the thorax in 39 (81.4\%) cases was small intestine, 38 (79.3\%) colon, 13 (27.1\%) liver, 20 (41.8\%) stomach, 2 (4.2\%) kidney and 22 (45.6\%) spleen. three $(4.3 \%)$ cases recurred. Brain ultrasound was normal in $88.4 \%$ of the neonates.

In the present study, 2.3\% had asphyxia, 7\% hemorrhage and $2.3 \%$ had a combination of the two latter pathologies. Skeletal anomaly revealed in $4.1 \%$ and congenital renal anomaly in $5.4 \%$ of the patients.

Echocardiography in $30 \%$ of all cases was normal. Pulmonary hypertension (PHTN) was seen in $21.8 \%$.

Forty-seven (63.5\%) cases survived and 27 (36.5\%) cases succumbed. The mean age of death was 28 (1-27) days. No correlation was found between sex and survival ( $\mathrm{P}$ value $=$ $0.84)$ and no meaningful relationship between Apgar at 5 minutes after birth survival (P value $=0.055)$ (Table 2 ).

The survival rate had a significant statistical correlation with the place of delivery. The death rates were higher in neonates referred from local hospitals in comparison to those from other cities $(\mathrm{P}=0.008)$. Also, the resuscitation history, the status at admission (intubated or not in- tubated $)(\mathrm{P}=0.00)$, skeletal anomalies $(\mathrm{P}=0.02)$ and brain hemorrhages $(\mathrm{P}=0.045)$ had a significant correlation with the survival rate. However, the direction of hernia, the herniated organs, type of operation (open or thoracoscopic), cardiac and renal anomalies and age at the time of surgery had no significant correlation with outcome.

Thoracoscopy was carried out in 7 neonates ( 5 males and 2 females with a mean age of 4 (2-6) days), 6 diaphragmatic defects were repaired successfully, and one case had to be switched to open surgery 10 minutes after starting because of hypercapnia. All were left-sided CDH. Complete repair with thoracoscope lasted in average 75 minutes (range 60 - 120 minutes).

During the surgery, there was no abnormal blood loss or other complications. The mean postoperative hospital stay was 14 (4 - 35) days. There was one single case of recurrence 7 days after repair that underwent open surgery and expired 2 weeks later. There was no abdominal compartment syndrome after the surgery. All patients were extubated one day after repair. The mean follow-up was 11 (6 36) months.

\section{Discussion}

Congenital diaphragmatic hernia, as an extensive congenital anomaly of the diaphragm, occurs 1 in 2500 to 4000 live births $(2,3)$. We planned this research to determine the factors influencing the prognosis of congenital diaphragmatic hernia. In our series, the most common (98.6\%) type of CDH was Bochdalek and in the left side (76.1\%). Only $10.8 \%$ of the patients were recognized prenatally, this had no effect on outcome of the disease. Also, the mode of delivery has no effect on prognosis $(\mathrm{P}=0.18)$. Prenatal diagnosis of $\mathrm{CDH}$ does not seem to justify decision for cesarean section. The survival rate in patients referred from local hospitals was lower than maternities from other cities $(\mathrm{P}=0.008)$. Possibly more critically ill CDH newborns died before arrival to our center. Positive history of resuscitation and need to intubation may be due to more severe form of illness. Some studies showed that herniation of liver or stomach into chest, was accompanied with a worse prognosis; however, we could not prove that $(\mathrm{P}=0.19)(4)$.

In most reports, the major reasons for mortality from CDH are pulmonary hyperplasia and pulmonary hypertension (5). Improvement in the skills used for neonatal intensive care and the advent of the "gentle ventilation" pointed to advances in the outcome of $\mathrm{CDH}$, with survival rates approximate to $80 \%$ - 90\% (6). However, the congenital diaphragmatic study teams, and many multicenter - and multicountry-based reports demonstrated a survival rate of roughly $70 \%(7,8)$. In this study, the survival rate of these neonates was $63.5 \%$. Mean age of the deceased was 28 (2 - 
Table 1. Patients' Characteristics $(n=74)$

\begin{tabular}{|c|c|}
\hline & Values $^{\mathrm{a}}$ \\
\hline \multicolumn{2}{|l|}{ Sex } \\
\hline Male & 64.4 \\
\hline Female & 35.6 \\
\hline Birth weight, $g$ & $2915.86 \pm 515$ \\
\hline \multicolumn{2}{|l|}{ Type of delivery } \\
\hline Natural vaginal delivery & 33.8 \\
\hline Cesarean section & 66.2 \\
\hline \multicolumn{2}{|l|}{ Apgar (5 min) } \\
\hline$<7$ & 25.9 \\
\hline$>7$ & 74.1 \\
\hline \multicolumn{2}{|l|}{ Prenatal diagnosis } \\
\hline Yes & 10.8 \\
\hline No & 89.2 \\
\hline Positive FH in CDH & 0 \\
\hline Positive FH in other anomalies & 2.7 \\
\hline Parental consanguinity & 27 \\
\hline Postnatal age at diagnosis, $\mathrm{d}$ & birth-28 \\
\hline Age at surgery, d & 1- 45 (mean: 8) \\
\hline Duration of mechanical ventilation, $d$ & $1-138$ (mean: 11.5$)$ \\
\hline Duration of hospital stay, d & 1-144 (mean: 20) \\
\hline \multicolumn{2}{|l|}{ Type of surgery } \\
\hline Open & 90.5 \\
\hline Thoracoscopy & 9.5 \\
\hline \multicolumn{2}{|l|}{ Type of hernia } \\
\hline Bochdaleck & 98.6 \\
\hline Morgagni & 1.4 \\
\hline \multicolumn{2}{|l|}{ Side of hernia } \\
\hline Left & 76.1 \\
\hline Right & 23.9 \\
\hline \multicolumn{2}{|l|}{ Herniated organs } \\
\hline Small intestine & 81.4 \\
\hline Colon & 79.3 \\
\hline Spleen & 45.6 \\
\hline Stomach & 41.8 \\
\hline Liver & 27.1 \\
\hline Kidney & 4.2 \\
\hline \multicolumn{2}{|l|}{ Associated anomalies } \\
\hline Cardiac & 70 \\
\hline Brain & 16 \\
\hline Kidney & 6.4 \\
\hline Skeletal & 4.1 \\
\hline \multicolumn{2}{|l|}{ Outcome } \\
\hline Survived & 63.5 \\
\hline Exit & 36.5 \\
\hline
\end{tabular}

Abbreviations: $\mathrm{CDH}$, congenital diaphragmatic hernia; $\mathrm{FH}$, family history.

${ }^{\mathrm{a}}$ Values are expressed as mean \pm SD or $\%$.

27) days. No correlation was found between sex and sur$\operatorname{vival}(\mathrm{P}=0.84)$, and no meaningful relationship was found between the Apgar score at birth and survival $(\mathrm{P}=0.055)$. The survival rate had a significant statistical correlation with the place of delivery, the death rates were higher in neonates referred from local hospitals in comparison to those coming from other cities $(\mathrm{P}=0.008)$. Also, resuscitation history, the status at admission (intubated or not intubated $)(P=0.00)$, skeletal anomalies $(P=0.02)$ and brain hemorrhage $(P=0.045)$ had a significant correlation with 
Table 2. Data Comparison in Survived and Deceased Infants ${ }^{\mathrm{a}}$

\begin{tabular}{|c|c|c|c|}
\hline & Survived $47(63.5 \%)$ & Deceased $27(36.5 \%)$ & PValue \\
\hline Sex & & & 0.846 \\
\hline Male & 63.8 & 36.2 & \\
\hline Female & 61.5 & 38.5 & \\
\hline Apgar & & & 0.055 \\
\hline Apgar $<7$ & 28.6 & 71.4 & \\
\hline Apgar $\geq 7$ & 70 & 30 & \\
\hline Delivery & & & 0.181 \\
\hline Vaginal & 54.2 & 45.8 & \\
\hline $\mathrm{C} / \mathrm{S}$ & 70.2 & 29.8 & \\
\hline Diagnosed prenatally & 37.5 & 62.5 & 0.106 \\
\hline Family history for CDH & 0 & 0 & 0.00 \\
\hline Family history for otheranomalies & 0 & $3(100)$ & 0.066 \\
\hline Parental consanguinity & 55 & 45 & 0.355 \\
\hline Delivery in local hospital & & & $0.008^{*}$ \\
\hline Delivery in other cities & 40.7 & 59.3 & \\
\hline & 73.7 & 26.3 & \\
\hline Resuscitation history & 22.7 & 77.3 & $0.00^{*}$ \\
\hline Status at admission & & & $0.00^{*}$ \\
\hline Intubated & 34.3 & 65.7 & \\
\hline Not intubated & 89.5 & 10.5 & \\
\hline Preoperative mechanical ventilation & 44.4 & 55.6 & $0.00^{*}$ \\
\hline Operation type & & & 0.549 \\
\hline Open & 71.9 & 28.1 & \\
\hline Thoracoscopy & 83.3 & 16.7 & \\
\hline \multicolumn{4}{|l|}{ Hernia type } \\
\hline Bochdalek & 63 & 37 & \\
\hline Morgagni & $1(100)$ & 0 & 0.866 \\
\hline Side of hernia & & & 0.248 \\
\hline Right & 76.5 & 23.5 & \\
\hline Left & 61.1 & 38.9 & \\
\hline Brain abnormality & 73.7 & 26.3 & $0.045^{*}$ \\
\hline Skeletal anomalies & & & $0.02 *$ \\
\hline Yes & 0 & 100 & \\
\hline No & 66.2 & 33.8 & \\
\hline
\end{tabular}

${ }^{\mathrm{a}}$ Values are expressed as \%.

the survival rate.

Persistent pulmonary hypertension remains a major cause of mortality and morbidity in CDH. Gosemann et al. (9) reported increased activation of NADPH oxidase in the pulmonary vasculature in experimental diaphragmatic hernia. In this study, echocardiography in 30\% of all patients was normal. Pulmonary hypertension was seen in $21.8 \%$.

Gomes Ferreira et al. (10) evaluated risk factors of failure after thoracoscopic repair. They found that the main limiting factor was persistent PHTN of the newborn. In this review, 9.5\% of the patients underwent thoracoscopic repair. All were stable before the surgery and without PHTN.

Casaccia et al. (11) collected retrospectively details of
113 high-risk CDH neonates, baseline demographics and disease characters. On the whole, the mortality rate was $41.6 \%$ (47/113). They recognized preoperative pneumothorax, birth weight below 2,500 $\mathrm{g}$ and liver herniation as independent mortality predictors, and female gender, higher gestational age and $\mathrm{aaO} 2$ more than $90 \mathrm{mmHg}$ as defensive factors. In this report, there was no correlation between sex and survival $(\mathrm{P}=0.84)$ and no meaningful relationship between Apgar score at birth and survival ( $\mathrm{P}=$ 0.055). Also, the direction of hernia, herniated organs in thorax, type of operation (open or thoracoscopic), cardiac and renal anomalies and age at the time of surgery had no significant correlation with outcome.

Bishay et al. (12) in a randomized controlled trial 
demonstrated that thoracoscopic repair of $\mathrm{CDH}$ is associated with prolonged and strict intra operative hypercapnia and acidosis, in contrast to open surgery. The consequence of thoracoscopy on blood gases through this procedure in neonates necessitates further assessment. The survival rate is reported about 68\% (13). In our brief experience with thoracoscopic repair, we had no intraoperative hypercapnia and acidosis.

The highest death risk in $\mathrm{CDH}$ was seen in patients related to extracorporeal membrane oxygenation (ECMO) with survival rates about 50\% to $65 \%$ (14). Even though preoperative stabilization and late surgery has established helpful for CDH patients not related to ECMO.

The optimal timing of $\mathrm{CDH}$ repairs in patients requiring ECMO remains controversial. Bryner (15) reported that $\mathrm{CDH}$ correction after the ECMO therapy had a better survival than repair on ECMO. Due to lack of this facility, the ECMO was used in none of our patients.

Fisher et al. (16) studied on neonates at risk for $\mathrm{CDH}$ recurrence. They recognized that age at repair and the diaphragm patch use were two factors for a higher risk of recurrence. They identified 24 (10\%) recurrences. In our experience, the rate of recurrence was $4.3 \%$.

With the increasing use of thoracoscopy by pediatric surgeons, a number of more difficult problems are being approached with this modality. On the other hand there are many advantages of thoracoscopy in children such as being less invasive, less painful, and having shorter hospital stay (17-20).

\subsection{Conclusions}

As progresses in prenatal evaluation and perinatal management have enhanced outcomes for neonates with congenital diaphragmatic hernia, importance has directed to the long-term follow-up of infants after surgical repair. It needs multidisciplinary $\mathrm{CDH}$ clinics and standard timelines for outpatient care .These patients need routine screening for $\mathrm{CDH}$ recurrence, a complication that leads to significant potential morbidity.

\section{References}

1. Colvin J, Bower C, Dickinson JE, Sokol J. Outcomes of congenital diaphragmatic hernia: a population-based study in Western Australia. Pediatrics. 2005;116(3):e356-63. doi: 10.1542/peds.2004-2845. [PubMed: 16140678].

2. Yang W, Carmichael SL, Harris JA, Shaw GM. Epidemiologic characteristics of congenital diaphragmatic hernia among 2.5 million California births, 1989-1997. Birth Defects Res A Clin Mol Teratol. 2006;76(3):1704. doi:10.1002/bdra.20230. [PubMed:16511883].

3. Gallot D, Boda C, Ughetto S, Perthus I, Robert-Gnansia E, Francannet $\mathrm{C}$, et al. Prenatal detection and outcome of congenital diaphragmatic hernia: a French registry-based study. Ultrasound Obstet Gynecol. 2007;29(3):276-83. doi:10.1002/uog.3863. [PubMed: 17177265].
4. Kitano Y, Okuyama H, Saito M, Usui N, Morikawa N, Masumoto K, et al. Re-evaluation of stomach position as a simple prognostic factor in fetal left congenital diaphragmatic hernia: a multicenter survey in Japan. Ultrasound Obstet Gynecol. 2011;37(3):277-82. doi: 10.1002/uog.8892. [PubMed: 21337653].

5. Logan JW, Rice HE, Goldberg RN, Cotten CM. Congenital diaphragmatic hernia: a systematic review and summary of bestevidence practice strategies. J Perinatol. 2007;27(9):535-49. doi: 10.1038/sj.jp.7211794. [PubMed: 17637787].

6. Masumoto K, Teshiba R, Esumi G, Nagata K, Takahata Y, Hikino S, et al. Improvement in the outcome of patients with antenatally diagnosed congenital diaphragmatic hernia using gentle ventilation and circulatory stabilization. Pediatr Surg Int. 2009;25(6):487-92. doi: 10.1007/s00383-009-2370-6. [PubMed: 19421756].

7. Congenital Diaphragmatic Hernia Study G, Lally KP, Lally PA, Lasky RE, Tibboel D, Jaksic T, et al. Defect size determines survival in infants with congenital diaphragmatic hernia. Pediatrics. 2007;120(3):e651-7. doi: 10.1542/peds.2006-3040. [PubMed: 17766505].

8. Tsao K, Lally KP. The Congenital Diaphragmatic Hernia Study Group: a voluntary international registry. Semin Pediatr Surg. 2008;17(2):90-7. doi: 10.1053/j.sempedsurg.2008.02.004. [PubMed: 18395658].

9. Gosemann JH, Friedmacher F, Hunziker M, Alvarez L, Corcionivoschi $\mathrm{N}$, Puri P. Increased activation of NADPH oxidase 4 in the pulmonary vasculature in experimental diaphragmatic hernia. Pediatr Surg Int. 2013;29(1):3-8. doi: 10.1007/s00383-012-3209-0. [PubMed: 23160901].

10. Gomes Ferreira C, Kuhn P, Lacreuse I, Kasleas C, Philippe P, Podevin $G$, et al. Congenital diaphragmatic hernia: an evaluation of risk factors for failure of thoracoscopic primary repair in neonates. $J$ Pediatr Surg. 2013;48(3):488-95. doi: 10.1016/j.jpedsurg.2012.09.060. [PubMed: 23480901].

11. Casaccia G, Rava L, Bagolan P, di Ciommo VM. Predictors and statistical models in congenital diaphragmatic hernia. Pediatr Surg Int. 2008;24(4):411-4. doi: 10.1007/s00383-008-2108-x. [PubMed: 18278505].

12. Bishay M, Giacomello L, Retrosi G, Thyoka M, Garriboli M, Brierley J, et al. Hypercapnia and acidosis during open and thoracoscopic repair of congenital diaphragmatic hernia and esophageal atresia: results of a pilot randomized controlled trial. Ann Surg. 2013;258(6):895-900. doi: 10.1097/SLA.0b013e31828fab55. [PubMed: 23604057].

13. The Congenital Diaphragmatic Hernia Study Group . Report from the Congenital Diaphragmatic Hernia Study Group 2008. Available from: http://cdhsg.net/CDHSG_Report.doc.

14. Morini F, Goldman A, Pierro A. Extracorporeal membrane oxygenation in infants with congenital diaphragmatic hernia: a systematic review of the evidence. Eur J Pediatr Surg. 2006;16(6):385-91. doi: 10.1055/s-2006-924751. [PubMed: 17211783].

15. Congenital Diaphragmatic Hernia Study G, Bryner BS, West BT, Hirschl RB, Drongowski RA, Lally KP, et al. Congenital diaphragmatic hernia requiring extracorporeal membrane oxygenation: does timing of repair matter?. J Pediatr Surg. 2009;44(6):1165-71. doi: 10.1016/j.jpedsurg.2009.02.022. [PubMed: 19524734] discussion 1171-2.

16. Fisher JC, Haley MJ, Ruiz-Elizalde A, Stolar CJ, Arkovitz MS. Multivariate model for predicting recurrence in congenital diaphragmatic hernia. J Pediatr Surg. 2009;44(6):1173-9. doi: 10.1016/j.jpedsurg.2009.02.043. [PubMed: 19524735] discussion 1179-80.

17. Gander JW, Fisher JC, Gross ER, Reichstein AR, Cowles RA, Aspelund G, et al. Early recurrence of congenital diaphragmatic hernia is higher after thoracoscopic than open repair: a single institutional study. J Pediatr Surg. 2011;46(7):1303-8. doi: 10.1016/j.jpedsurg.2010.11.048. [PubMed: 21763826].

18. Tsao K, Lally PA, Lally KP, Congenital Diaphragmatic Hernia Study G. Minimally invasive repair of congenital diaphragmatic hernia. $J$ Pediatr Surg. 2011;46(6):1158-64. doi: 10.1016/j.jpedsurg.2011.03.050. [PubMed: 21683215]. 
19. Okazaki T, Nishimura K, Takahashi T, Shoji H, Shimizu T, Tanaka T, et al. Indications for thoracoscopic repair of congenital diaphragmatic hernia in neonates. Pediatr Surg Int. 2011;27(1):35-8. doi: 10.1007/s00383-010-2724-0. [PubMed: 20852868].
20. Shalaby R, Gabr K, Al-Saied G, Ibrahem M, Shams AM, Dorgham A, et al Thoracoscopic repair of diaphragmatic hernia in neonates and children: a new simplified technique. Pediatr Surg Int. 2008;24(5):543-7. doi: 10.1007/s00383-008-2128-6. [PubMed: 18351362]. 